\title{
FIgll-28 Is a Major Flagellin-Derived Defense Elicitor in Potato
}

\author{
Natalia Moroz and Kiwamu Tanaka \\ Department of Plant Pathology, Washington State University, Pullman, WA 99164-6430, U.S.A.
}

Accepted 21 October 2019.

\begin{abstract}
The first layer of plant immunity is deployed by recognition of pathogen-associated molecule patterns (PAMPs) and induction of early stress responses. Flagellin is the major protein component of the flagellum. Flagellin-derived peptide fragments such as Flg22, a short active peptide derived from the highly conserved part of the $\mathrm{N}$-terminal region, are recognized as PAMPs by a specific perception system present in most higher plants. Some bacteria evade the plant recognition system by altering the Flg22 region in the flagellin. Instead, a small subset of plants (i.e., solanaceous plants) can sense these bacteria by recognizing a second region, termed FlgII-28. The function of FlgII-28 has been well-documented in tomato but not in potato plants. Here, we investigated the effect of FlgII-28 on several defense responses in potato. Cytosolic calcium $\left(\mathrm{Ca}^{2+}\right)$ elevation is an early defense response upon pathogenic infection. We generated transgenic potato plants expressing aequorin, a nontoxic $\mathrm{Ca}^{2+}$-activated photoprotein. The results showed that FlgII-28 induced strong cytosolic $\mathrm{Ca}^{2+}$ elevation in a dosedependent manner, whereas the response was attenuated when a $\mathrm{Ca}^{2+}$ channel blocker was added. In addition, the FlgII-28triggered cytosolic $\mathrm{Ca}^{2+}$ elevation was shown to subsequently promote extracellular alkalinization, reactive oxygen species production, mitogen-activated protein kinase phosphorylation, and transcriptional reprogramming of defense-related genes in potato. Interestingly, all tested defense responses caused by FlgII-28 were significantly stronger than those caused by Flg22, suggesting that FlgII-28 acts as a primary flagellar PAMP to elicit multiple defense responses in potato.
\end{abstract}

Keywords: cytosolic calcium, early defense response, flagellin, FlgII-28, Flg22, transgenic potato

Plants have a sophisticated, multilayered immune system that comprises pathogen-associated molecular pattern (PAMP)triggered immunity (PTI) and effector-triggered immunity (Jones and Dangl 2006) as mechanisms of perception of nonself molecules. In addition, plants can also activate immune

${ }^{\dagger}$ Corresponding author: K. Tanaka; kiwamu.tanaka@wsu.edu

Funding: This work was supported by the United States Department of Agriculture National Institute of Food and Agriculture, Hatch project 1015621 and AFRI grant award 2019-67013-29963, and the Northwest Potato Research Consortium.

*The $\boldsymbol{e}$-Xtra logo stands for "electronic extra" and indicates that supplementary material is published online.

The author(s) declare no conflict of interest.

๑) 2020 The American Phytopathological Society responses by perceiving host-derived molecules or damageassociated molecular patterns (DAMPs) (Tanaka et al. 2014).

PAMPs are conserved molecular structures produced by pathogens and recognized by pattern recognition receptors (PRRs). The PAMP-PRR interaction elicits early immune responses, such as rapid and transient cytosolic calcium $\left(\mathrm{Ca}^{2+}\right)$ elevation, reactive oxygen species (ROS) production (Rosli et al. 2013), extracellular alkalinization, mitogen-activated protein (MAP) kinase phosphorylation, and transcriptional reprogramming of defense-related genes (Nürnberger and Brunner 2002). Structural requirements in PAMPs for pathogen recognition and host defense responses may vary among different plant species.

Flagellated bacterial pathogens are recognized by the plant immune system mostly by sensing flagellin, a primary component of the flagellum, as a PAMP. PRRs of different plants sense distinct parts of flagellin. For example, the FLAGELLINSENSING 2 (FLS2) receptor that is present in many angiosperms detects Flg22, one of the highly conserved N-terminal peptides of bacterial flagellin, while an as-yet-unknown receptor (FLSx) in rice recognizes a different part of the flagellin molecule called CD2-1 (Fliegmann and Felix 2016). Recently, the FLS3 receptor that is present in a subset of the Solanaceae family was identified as a PRR that recognizes FlgII-28, another region in flagellin (Hind et al. 2016).

Some bacteria evade the plant recognition system by altering sequence in their flagellin region. For instance, aberrant Flg22 from Liberibacter solanacearum and Liberibacter asiaticus was shown to not induce ROS production in tobacco, tomato, or potato, while Flg22 from Pseudomonas aeruginosa triggered ROS in all three plant species (Hao et al. 2014). FlgII-28 was originally discovered in $P$. syringae pv. tomato T1 lineage as a specific PAMP for a few solanaceous species, including tomato, potato, and pepper (Cai et al. 2011). Some P. syringae pv. tomato strains have mutations in FlgII-28 (e.g., FlgII-28 $8_{\mathrm{k} 40}$ and FlgII-28 $\left.8_{\mathrm{Col} 338}\right)$ that were reported to trigger a weak immune response in tomato and cause typical outbreaks of bacterial speck disease (Cai et al. 2011). Interestingly, the destructive pathogen Ralstonia solanacearum, which causes bacterial wilt, has aberrant flagellin. In this case, most species in the Solanaceae family are unable to perceive the flagellin-derived peptides of this bacterial pathogen (Wei et al. 2018). In addition, the strength of defense responses caused by FlgII-28 is variable in different tomato genotypes (Bhattarai et al. 2016; Cai et al. 2011; Veluchamy et al. 2014). Indeed, some tomato varieties and a wild tomato species (Solanum pimpinellifolium) lack the PTI response to FlgII-28. This finding led to the identification of the FLS3 receptor, which specifically recognizes FlgII-28, distinct from Flg22, in the flagellin molecule (Hind et al. 2016). This result suggests that the structural requirements for pathogen recognition vary significantly even in the same species. 
The effect of FlgII-28 is relatively well-studied in tomato plants, whereas limited information is available in potato plants. Here, using potato plants, we demonstrated that i) FlgII-28 stimulated strong cytosolic $\mathrm{Ca}^{2+}$ elevation in potato in a dose-dependent manner; ii) FigII-28 triggered downstream defense responses, i.e., ROS production, extracellular alkalinization, MAP kinase phosphorylation, and transcriptional reprograming of defense-related genes, all of which required cytosolic $\mathrm{Ca}^{2+}$ elevation; and iii) responsiveness to FigII-28 was significantly greater than that to Flg22. Our results demonstrate that FlgII-28 elicits multiple defense responses and acts as a primary PAMP for bacterial flagellin recognition in potato.

\section{RESULTS}

Generation of aequorin-expressing transgenic potato.

Cytosolic $\mathrm{Ca}^{2+}$ elevation is one of the earliest cellular responses to external stimuli. To measure changes in cytosolic free $\mathrm{Ca}^{2+}$ concentration $\left(\left[\mathrm{Ca}^{2+}\right]_{\text {cyt }}\right)$ in potato, we generated aequorin-expressing transgenic potato. Internodal segments of potato cv. Désirée plants were inoculated with Agrobacterium tumefaciens carrying the $\mathrm{pBINU}-\mathrm{YA}(\mathrm{K})$ plasmid, including a yellow fluorescent protein (YFP)-fused aequorin gene driven by the ubiquitin promoter UBI10 (Supplementary Fig. S1A). Seven of 250 internodes had regenerated plantlets (each internode has five to 100 plantlets); a total of 275 platelets were transferred (Supplementary Fig. S1B) and were further grown on antibiotic-based selection medium in individual glass test tubes (Supplementary Fig. S1C). Successfully grown plantlets were further selected under the microscope by confirming fluorescence from the YFP expressed (Supplementary Fig. S1D and E). Additionally, the YFP expression level was tested by immunoblotting using a monoclonal green fluorescent protein (GFP) antibody (Supplementary Fig. S1F). We also measured the expression level of aequorin by directly measuring aequorin enzymatic activity using a discharging protocol (details are provided below). The results demonstrated that the expression level of aequorin was correlated with that of YFP (Supplementary Fig. S1F and G). Finally, screening was performed by ensuring that the plantlets did not have any malformed phenotype and eight transgenic lines were selected to be used for the downstream experiments.

We next assessed the level of aequorin expression for the eight transgenic lines in different plant organs, i.e., leaves, nodes, stem pieces (internodes), and root tips, from 4-week-old potato clones (hereafter, individual regenerated plants of independent transgenic lines are referred to as clones). The expression of aequorin was tested at saturating $\mathrm{Ca}^{2+}$ concentrations using a discharging protocol (details below). While aequorin expression was detected in all the tested plant organs, the level in root tips was higher than that in any other tissues tested (Supplementary Fig. S2A).

We also determined whether the aequorin expression level was affected by the age of the transgenic potato clones. The results showed that aequorin expression in leaves of 2-week-old plants was approximately two times higher than that in 4- and 6-week-old plants (Supplementary Fig. S2B). However, we decided to use 4- to 6-week-old clones for the downstream experiments because the small size of 2 -week-old potato plants and leaves, in particular, leads to difficulty in the collection of enough plant tissue for the experiments.

\section{FlgII-28 induces $\left[\mathrm{Ca}^{2+}\right]_{c y t}$ elevation in potato.}

The leaves of various transgenic potato clones (cv. Désirée) were screened for the level of $\left[\mathrm{Ca}^{2+}\right]_{\text {cyt }}$ elevation initiated by FlgII28 (derived from T1 lineage). The increase in $\left[\mathrm{Ca}^{2+}\right]_{\mathrm{cyt}}$ varied up to twofold for different clones; however, detectable changes in $\left[\mathrm{Ca}^{2+}\right]_{\mathrm{cyt}}$ were observed for all tested clones within the first $60 \mathrm{~s}$ after elicitor injection, and the maximum photon counts appeared within the next $60 \mathrm{~s}$ This observation indicated that all clones responded similarly to the elicitor, even though the level of aequorin expression varied among the clones. Based on our results, clones 2-4, 2-26, 2-30, 2-65, 2$77,2-88$, and 3-65 were used in the subsequent experiments (Supplementary Fig. S3).

We assessed the immune-eliciting effect of FlgII-28 on $\left[\mathrm{Ca}^{2+}\right]_{\text {cyt }}$ elevation in different plant organs, such as leaves, nodes, internodes, and root tips. In our study, the effect of FlgII28 was compared with that of the other well-known elicitors, potato DAMP systemin (StSystemin) and the fungal PAMP chitin. All three stimulants were applied at a $1 \mu \mathrm{M}$ concentration, and the chemiluminescence signal was monitored during the first 8 min after application (Fig. 1). We found that FlgII-28 elicited the highest induction of $\left[\mathrm{Ca}^{2+}\right]_{\text {cyt }}$ elevation in leaves, nodes, and internodes, while the elevation in root tips was comparable with that induced by StSystemin and chitin.

Next, we examined the dose-dependent effect of FlgII-28 on the $\left[\mathrm{Ca}^{2+}\right]_{\text {cyt }}$ response (Fig. 2). FlgII-28 was applied to potato leaves at concentrations of $1.0,0.5$, and $0.1 \mu \mathrm{M}$. A dosedependent increase in the FlgII-28-induced $\left[\mathrm{Ca}^{2+}\right]_{\text {cyt }}$ response was observed. (Fig. 2A).

The following step was performed to evaluate whether the $\left[\mathrm{Ca}^{2+}\right]_{\text {cyt }}$ response by FlgII-28 could be attenuated in the presence of a $\mathrm{Ca}^{2+}$ channel blocker, gadolinium $\mathrm{Gd}^{3+}$ (Kaplan et al. 2006; Katicheva et al. 2015; Klüsener et al. 1995; Lecourieux et al. 2002; Yang and Sachs 1989). Potato leaves were pretreated for 30 min with $\mathrm{Gd}^{3+}$ at concentrations from 0.1 to $5 \mathrm{mM}$, followed by the addition of $1 \mu \mathrm{M}$ FlgII-28. A substantial decrease in the detectable $\left[\mathrm{Ca}^{2+}\right]_{\text {cyt }}$ response and retardation of the peak appearance were observed in a $\mathrm{Gd}^{3+}$-dose-dependent manner (Fig. 2B).

\section{FlgII-28 induces ROS production dependent on $\mathrm{Ca}^{2+}$ influx in potato.}

Oxidative burst, one of the early defense responses, is the rapid release of ROS from plant cells following perception of PAMPs and DAMPs. To test the effect of FlgII-28 on ROS production in potato, we performed a luminol-based chemiluminescence measurement using leaf discs from various potato cultivars (Supplementary Fig. S4). We observed different responses in ROS production among eight different cultivars tested, with higher responses for cvs. Hokkai-Kogane, Mesa Russet, Eniwa, Russet Burbank, and Shepody, and the weaker responses for cvs. Désirée, Kamiyaimo and Early Gem. The responsiveness to FlgII-28 might reflect the strength of bacterial disease resistance in each potato cultivar.

We next assessed whether FlgII-28-induced ROS production is dependent on $\mathrm{Ca}^{2+}$ influx in the representative cvs. Désirée, Russet Burbank, Mesa Russet, and Hokkai-Kogane (Fig. 3). Potato leaf discs were pretreated with $1 \mathrm{mM} \mathrm{Gd}^{3+}$ for $30 \mathrm{~min}$, and then, $1 \mu \mathrm{M}$ FlgII-28 with oxidative burst solution was added after $\mathrm{Gd}^{3+}$ was washed away by sterile deionized water. The results showed that the effect of FlgII-28 was significantly inhibited by $\mathrm{Gd}^{3+}$ in all cultivars tested, while the $\mathrm{Ca}^{2+}$ channel blocker alone did not facilitate the generation of ROS (Fig. 3), suggesting that FlgII-28-induced ROS production occurs downstream of FlgII28 -induced $\mathrm{Ca}^{2+}$ influx.

\section{FlgII-28 induces defense-related gene expression dependent on $\mathrm{Ca}^{2+}$ influx in potato.}

We further tested the effect of FlgII-28 on the downstream transcription of potato defense-related genes. Total RNA extraction was performed from potato leaves (cv. Désirée) following treatment with FlgII-28 with or without the $\mathrm{Ca}^{2+}$ channel blocker $\mathrm{Gd}^{3+}$. The transcription of several potato 
defense-related genes was quantified by real-time quantitative reverse transcription (qRT)-PCR (Supplementary Table S1 provides details on the marker genes and primer sequences). The housekeeping genes EFI $a$ and $U b q$ were used as reference genes for quantitative analysis (Nicot et al. 2005). The result showed that a 30-min treatment of FlgII-28 upregulated gene expression of StPAL-1, StPAL-2, and StERF3 (fold change = $3.5,2.5$, and 2.0, respectively), whereas StPR-1b, StPR-5 were down-regulated (fold change $=2.0$ for both genes) (Fig. 4). Increasing the time of FlgII-28 treatment up to $6 \mathrm{~h}$ led to the upregulation of $S t P R-1 b, S t P R-2, S t P R-5, S t P R-10$ (fold change $=2.0,1.7,3.5$, and 5.0, respectively), StDefensin, and StSAUR2 (fold change $=2.5$ and 3.0, respectively), in addition to StPAL1 and StPAL2 and StERF3 (fold change = 3.7, 3.7, and 2.1 , respectively). To a greater or lesser extent, $\mathrm{Gd}^{3+}$ attenuated FlgII-28-induced upregulation of all genes at both tested timepoints, indicating dependence on $\mathrm{Ca}^{2+}$ influx.

\section{FlgII-28 induces extracellular alkalinization dependent} on $\mathrm{Ca}^{2+}$ influx in potato.

Extracellular alkalinization is one of the early defense responses in plants (Moroz et al. 2017a). We set up the extracellular alkalinization assay using potato suspension culture derived from tubers. Potato cv. Russet Burbank was used in this experiment because this is the only cultivar available as suspension culture cells in our laboratory. As shown in Figures 5 and $6 \mathrm{E}$, FlgII-28 induced upregulation of extracellular $\mathrm{pH}$ within $30 \mathrm{~min}$. To further test whether FlgII-28-induced extracellular alkalinization depends on $\mathrm{Ca}^{2+}$ influx, $\mathrm{Gd}^{3+}$ at concentration of $0.01,0.1,1$, or $5 \mathrm{mM}$ was applied to potato suspension cells for $30 \mathrm{~min}$ prior to the addition of FlgII-28 (Fig. 5A, Gd ${ }^{3+} /$ FlgII-28), while water was applied as a mock treatment (Fig. $5 \mathrm{~A}, \mathrm{Gd}^{3+} / \mathrm{H}_{2} \mathrm{O}$ ). It has been known that $\mathrm{Gd}^{3+}$ (and also $\mathrm{La}^{3+}$ ) precipitates phosphates in Murashige Skoog (MS) medium since it has strong affinity for anions, e.g., $\mathrm{PO}_{4}{ }^{3-}$ (RuízHerrera et al. 2012; De Vriese et al. 2018). To avoid $\mathrm{Gd}^{3+}$ precipitation, suspension culture was transferred to phosphate-free media and was allowed to acclimate for 3 days prior to the addition of stimulants. Even though $\mathrm{Gd}^{3+}$ did not change $\mathrm{pH}$ when it was supplied in cell-free medium, we observed an acidification as a side effect of $\mathrm{Gd}^{3+}$ in the medium with potato cells, for unknown reasons (Fig. 5A). As a solution, FlgII-28-triggered extracellular alkalinization in the presence of $\mathrm{Gd}^{3+}$ was evaluated in $\Delta \Delta \mathrm{pH}$ that was calculated using the following equation:
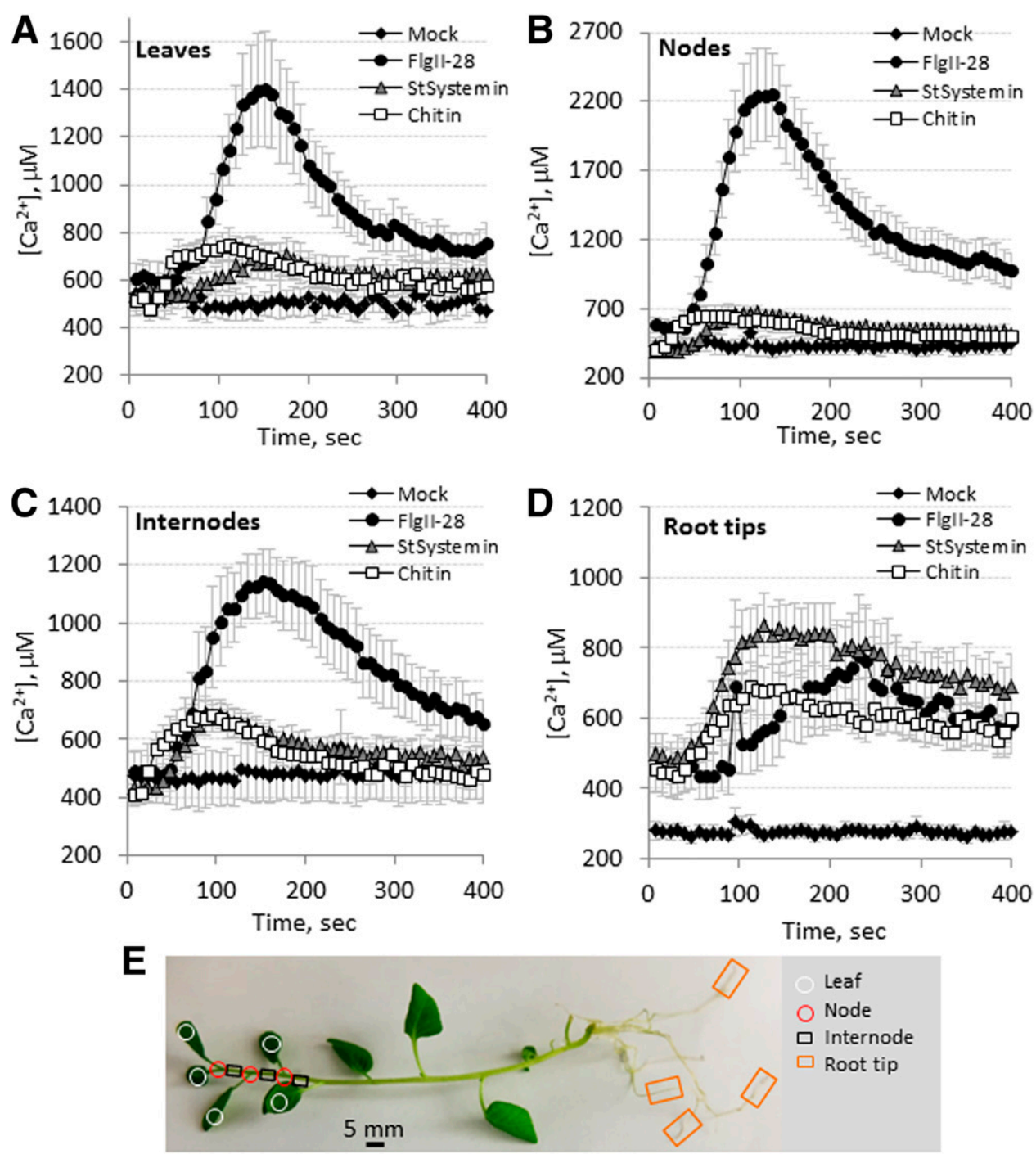

Fig. 1. Kinetics of the elicitor-induced $\left[\mathrm{Ca}^{2+}\right]_{\text {cyt }}$ elevation in the different organs of potato. A, Leaf discs in 5-mm diameter, B, 5-mm-long nodes, C, 5-mm-long internodes, and D, 10-mm-long root with root tips from the 6-week-old aequorin-expressing transgenic potato cv. Désirée (clone 2-65) were treated with FlgII28 , StSystemin, and chitin hexamer at a final concentration of $1 \mu \mathrm{M}$ each. Elicitors were automatically dispensed at time 0 in the graphs. Mean \pm standard error, $n=8$. E, Representative image of the potato plant denoting plant organs used for the experiment. 
$\Delta \Delta \mathrm{pH}=\Delta \mathrm{pH}_{\mathrm{Gd} 3+/ \mathrm{FlgII}-28}-\Delta \mathrm{pH}_{\mathrm{Gd} 3+/ \mathrm{H} 2 \mathrm{O}}$. Based on the results shown in Figure $5 \mathrm{~B}$, complete inhibition of FlgII-28-induced extracellular alkalinization was observed when $5 \mathrm{mM}^{3} \mathrm{Gd}^{3+}$ was added, and half-inhibition was caused by $1 \mathrm{mM} \mathrm{Gd}^{3+}$, while no inhibition was detected in a culture supplemented with $<0.1 \mathrm{mM}$ $\mathrm{Gd}^{3+}$ (Fig. 5B). Our data are in good agreement with previously published results (Schaller and Oecking 1999), in which, using $\mathrm{La}^{3+}$, another well-known calcium channel blocker, in phosphatefree MS medium, systemin-induced $\mathrm{Ca}^{2+}$ elevation was shown to be required for extracellular alkalinization in tomato, although the authors made no mention of acidification potentially caused by the supplemented trivalent metal.

\section{FlgII-28 triggers significantly greater defense responses than Flg22 in potato.}

The eliciting activity of FlgII-28 in potato was compared with that of the well-known bacterial peptide Flg22 (Fig. 6). Using the aequorin-expressing transgenic potato clone 3-65, the effect of $1 \mu \mathrm{M}$ FlgII-28 on $\left[\mathrm{Ca}^{2+}\right]_{\text {cyt }}$ was reproduced as significant responses in leaves, nodes, and internodes and a relatively weak response in root tips (Fig. 6A). In contrast with FlgII-28, the $\left[\mathrm{Ca}^{2+}\right]_{\text {cyt }}$ value after treatment with $1 \mu \mathrm{M}$ Flg22 was significantly lower, and the response was detectable in only nodes and internodes (Fig. 6B).

We also tested both bacterial elicitors in the ROS assay, demonstrating that the ROS production induced by both bacterial elicitors in nodes was two times that observed in internodes and approximately 10 times higher than in leaves and root tips, but again, the effect of FlgII-28 was five times greater than that of Flg22 (Fig. 6C and D).

A significant difference in the defense response to FlgII-28 and Flg22 in potato was confirmed by an extracellular alkalinization assay using potato suspension cell culture. The effect of $1 \mu \mathrm{M}$ FlgII-28 on extracellular alkalinization was detected at $5 \mathrm{~min}$ and continued to rise during next $10 \mathrm{~min}$, while the effect of $1 \mu \mathrm{M}$ Flg22 was scarce (Fig. 6E).

MAP kinase cascades play pivotal roles in plant innate immunity. Phosphorylation of MAP kinases is an excellent marker for detection of defense responses. To test the potential difference in potato kinase activation by the two bacterial PAMPs, leaves from potato clone $2-4$ were treated with $1 \mu \mathrm{M}$ Flg22 or
$1 \mu \mathrm{M}$ FlgII-28 for $10 \mathrm{~min}$. Proteins from total extracts were subjected to Western blot analysis using an antiphospho-MAP kinase antibody. Proteins from Arabidopsis seedlings were used as a positive control to demonstrate Flg22-induced elicitation (Fig. 6F), exhibiting three visible bands corresponding to the phosphorylated MAP kinases AtMPK6 (45 kDa), AtMPK3 (42 kDa), and AtMPK4 (38 kDa). In potato, Flg22 treatment did not result in any detectable MAPK phosphorylation, while FlgII-28 induced a strong band likely corresponding to StMPK6 (45.6 kDa, GenBank AHN53386). In contrast, FlgII-28 did not cause any MAP kinase phosphorylation in Arabidopsis.

Additionally, we tested whether FlgII-28-induced MAP kinase phosphorylation in potato is dependent on $\mathrm{Ca}^{2+}$ influx. Potato leaves were preincubated with the $\mathrm{Ca}^{2+}$ channel blocker $\mathrm{Gd}^{3+}$ for $30 \mathrm{~min}$, and then, $1 \mu \mathrm{M}$ FlgII-28 was added for 10 min (Fig. 6G). The results showed that the $\mathrm{Ca}^{2+}$ channel blocker completely attenuated FlgII-28-stimulated StMPK6 phosphorylation. No bands were detected after preincubation with $\mathrm{Gd}^{3+}$.

\section{DISCUSSION}

In this study, we demonstrated the strong and specific effect of the bacterial elicitor FlgII-28 on multiple defense responses in potato, e.g., $\left[\mathrm{Ca}^{2+}\right]_{\text {cyt }}$ elevation, ROS production, extracellular alkalinization, MAP kinase phosphorylation, and reprogramming of defense-related genes, most of which are dependent on $\mathrm{Ca}^{2+}$ influx. Interestingly, the defense responses induced by FlgII-28 in potato were significantly greater than those induced by the well-studied bacterial PAMP Flg22 that is recognized by multiple clades of seed plants belonging to angiosperms and even gymnosperms (Albert et al. 2010; Felix et al. 1999).

Tissue-dependent response to bacterial PAMPs in potato.

Like other plants, potato plants respond to pathogens in a spatio-temporal manner. For example, potato leaves exhibited a visible disease symptom at $24 \mathrm{~h}$ postinfection by the bacterial pathogen Pectobacterium carotovora (formerly Erwinia carotovora), while it took $48 \mathrm{~h}$ for tubers (Poiatti et al. 2009). Moreover, another bacterial pathogen, Xanthomonas
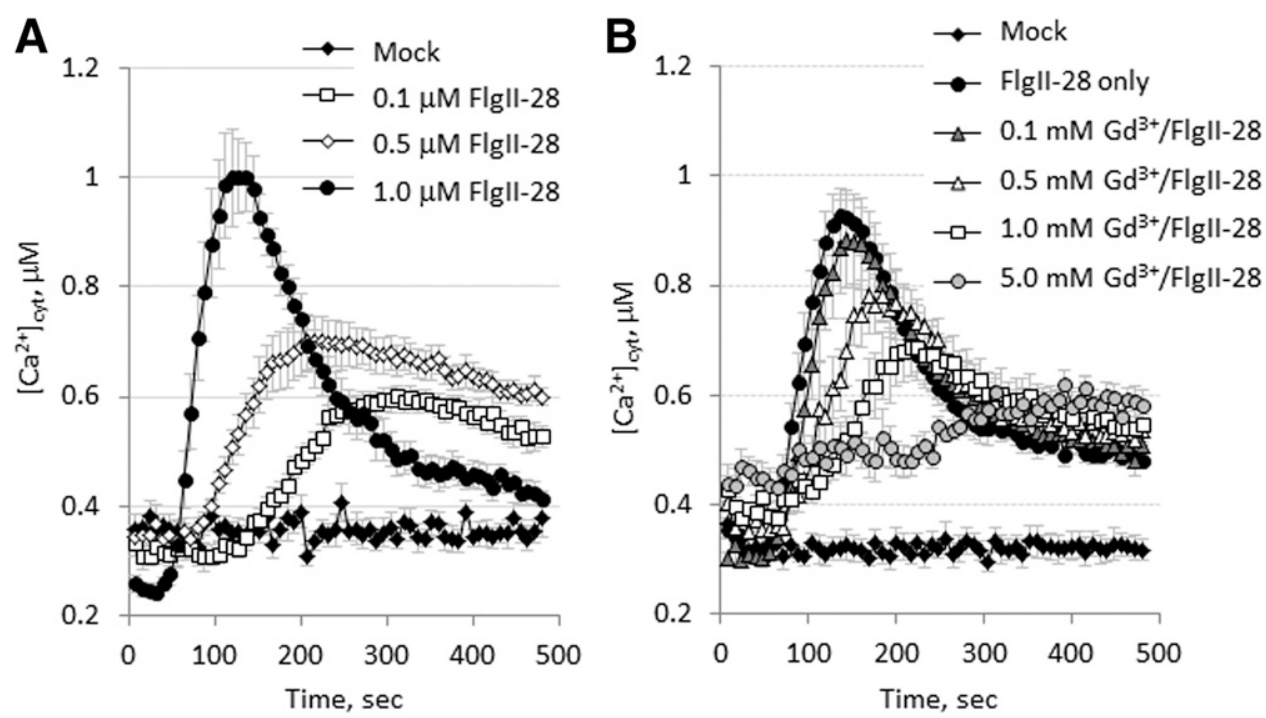

Fig. 2. Dose-dependent effect of FlgII-28 on $\left[\mathrm{Ca}^{2+}\right]_{\text {cyt }}$ elevation in potato. A, FlgII-28 at a final concentration of $0.1,0.5$, or $1 \mu \mathrm{M}$ was dispensed to leaf discs ( $5 \mathrm{~mm}$ diameter) of the aequorin-expressing transgenic potato cv. Désirée (clone 2-65). B, The Ca $\mathrm{Can}^{2+}$ channel blocker Gd $^{3+}$ inhibits $1 \mu \mathrm{M}-\mathrm{FlgII}-28$-stimulated

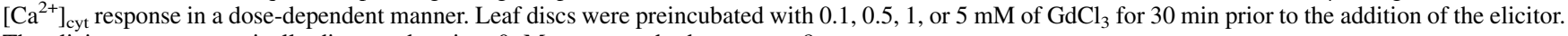
The elicitor was automatically dispensed at time 0 . Mean \pm standard error, $n=8$. 
axonopodis, caused a hypersensitive response in leaves but not in tubers (Poiatti et al. 2009). Our data indicated that potato plant stems (nodes and internodes) followed by leaves exhibited much stronger defense responses to bacterial PAMPs (i.e., Flg22 and FlgII-28) than root tips that do not contain much vascular tissue. It is possible that the vasculature is more sensitive to bacterial PAMPs, given that many destructive bacterial pathogens infect the plant vascular system (Jacobs et al. 2012; Vinatzer 2012). Indeed, the FLS2 receptor in Arabidopsis is highly expressed in the vasculature throughout the aerial part and roots, whereas the basal expression of this protein was not measurable in root tips (Beck et al. 2014). Intriguingly, even PEPR1 and PEPR2, receptors of the DAMP AtPEPs, are also highly expressed in vascular tissue (Bartels et al. 2013). Although no information is available regarding the distribution of the FLS3 receptor in potato plants, our data suggested that potato FLS3 could be expressing in a similar manner as FLS2 in Arabidopsis. A recent report demonstrated that Flg22 is systemically transported through vascular connections, for which internalization of Flg22 into plant cells via recognition by FLS2-BAK1 coreceptors is required (Jelenska et al. 2017). This evidence also indicates that recognition of PAMPs (also DAMPs) in the vascular system plays a critical role in plant immune responses. Future studies focused on exploring any correlation between tissue-specific disease severity and FlgII-28-FLS3-induced defense responses (e.g., $\left[\mathrm{Ca}^{2+}\right]_{\text {cyt }}$ elevation), using as many potato germplasms as possible, might provide a better understanding on the biological significance of FlgII-28-FLS3-mediated immunity in a tissue-specific manner in potato.

\section{$\mathrm{Ca}^{+2}$ influx is the most upstream event \\ in FlgII-28-mediated signaling.}

Our results demonstrated that FlgII-28-induced $\left[\mathrm{Ca}^{2+}\right]_{\mathrm{cyt}}$ elevation is required for other defense responses, such as ROS production, MAP kinase phosphorylation, and expression of defense-related genes, suggesting that $\mathrm{Ca}^{2+}$ influx is a farupstream event in FlgII-28-mediated signaling. However, given that $\mathrm{Ca}^{2+}$ - and ROS-mediated signaling amplify each other in the plant immune response (Marcec et al. 2019), one can hypothesize that FLS3-mediated FlgII-28 signaling activates $\mathrm{Ca}^{2+}$ influx in parallel with ROS generation by controlling NADPH oxidases (NOXs) located in the plasma membrane. It has been reported that FLS2-mediated Flg22 signaling directly activates a NOX protein, RBOHD, via phosphorylation of this protein by a receptor-like cytoplasmic kinase, BIK1 (Kadota et al. 2014). The signaling pathway between potato FLS3 and NOXs remains to be elucidated.

\section{FlgII-28 is a major flagellin-derived defense elicitor in potato.}

Flagellin-derived PAMPs were shown to play a major role in bacterial recognition in tomato (Rosli et al. 2013), in which an RNA sequencing approach demonstrated very little transcriptional reprogramming upon infection with the $P$. syringae pv. tomato DC3000 $\Delta$ hrcQ-U $\Delta$ fliC mutant, lacking a functional type three secretion system and flagellin, while the wild-type $P$. syringae pv. tomato strain and FlgII-28 initiated comparable expressions of thousands of PTI-associated genes (Rosli et al. 2013). In addition, the percentage of FlgII-28-induced protein kinase genes, which are important for immune response in
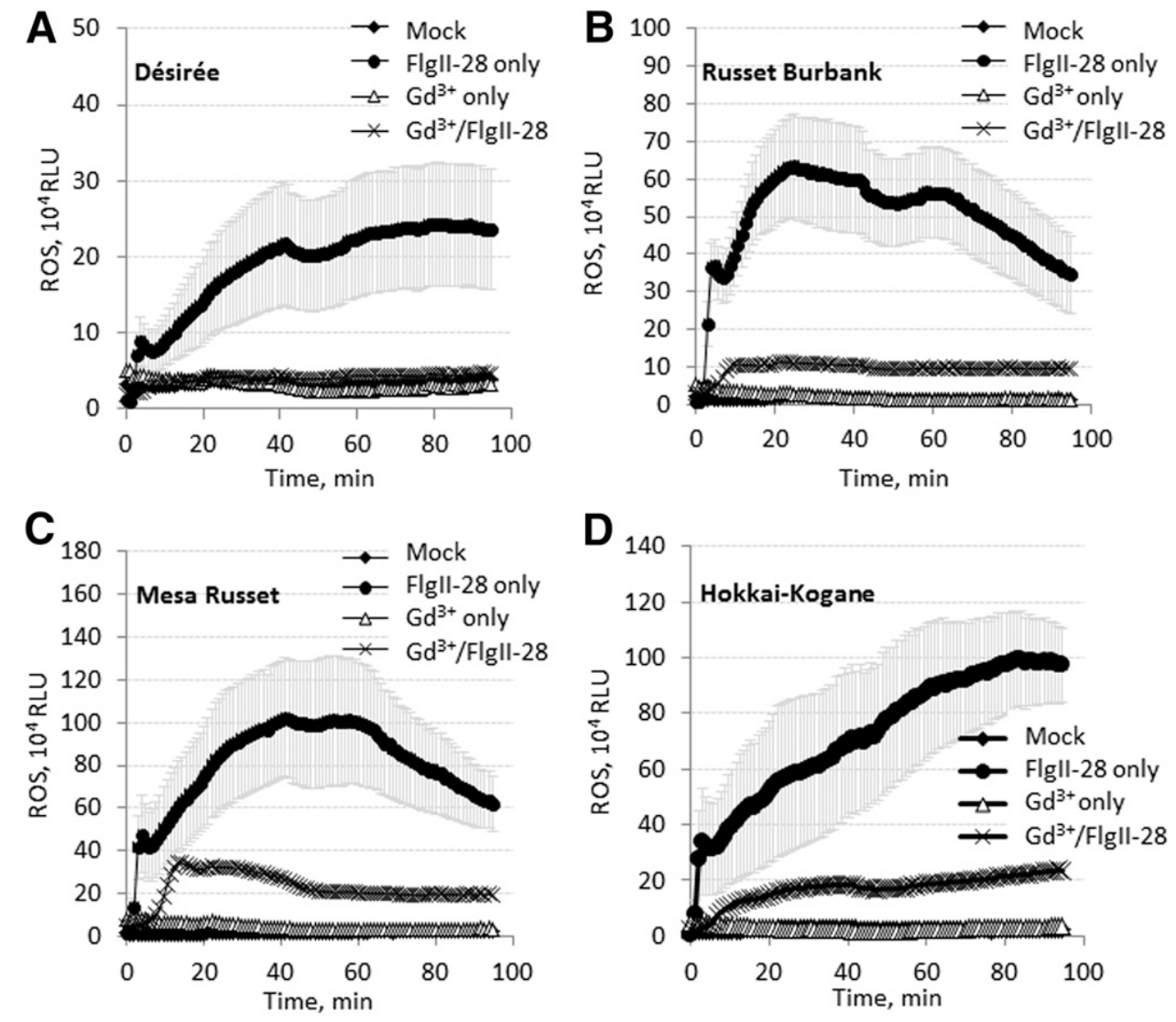

Fig. 3. FlgII-28-induced reactive oxygen species production is dependent on $\mathrm{Ca}^{2+}$ influx in potato. A, FlgII- 28 was automatically dispensed at time 0 to the final concentration of $1 \mu \mathrm{M}$ to 5-mm leaf discs of potato cultivars Désirée, B, Russet Burbank, C, Mesa Russet, and D, Hokkai-Kogane. To test the effect of the Ca ${ }^{2+}$ channel blocker $\mathrm{Gd}^{3+}$, leaf samples were preincubated with $1 \mathrm{mM} \mathrm{GdCl}$ for 30 min prior to the addition of FlgII-28. Error did not exceed $20 \%$. Mean \pm standard error, $n=8$. 
tomato, was shown to be similar to that observed in Arabidopsis upon Flg22 treatment (Rosli et al. 2013). These data suggested that FlgII-28-mediated PTI is likely a typical defense pathway in tomato and other members of the Solanaceae family. This was corroborated by our qRT-PCR data that demonstrated FlgII-28-induced expression of canonical defense-related genes in potato (Fig. 4).

As shown in Figures 1 and 6, the effect of FlgII-28 on the $\left[\mathrm{Ca}^{2+}\right]_{\text {cyt }}$ response was much stronger than that of other wellknown PAMPs (Flg22 and chitin) and a DAMP (potato systemin) in potato. In particular, the difference between the FlgII-28- and Flg22-induced $\left[\mathrm{Ca}^{2+}\right]_{\text {cyt }}$ responses was marked, and a similar difference was also observed in the results for ROS production, extracellular alkalinization, and MAP kinase phosphorylation (Fig. 6). These results are consistent with a previous finding on ROS production in potato cv. Red Maria (Clarke et al. 2013). Our results on ROS production by FlgII-28 further revealed a similar response (FlgII-28 > Flg22) in various potato cultivars (Fig. 6; Supplementary Fig. S4), although the intensity of the response varied among the potato cultivars, which demonstrates that sensitivity to PAMPs differs significantly not only among species of the same family but also among different genotypes of the same species. Previously, differential PAMP-triggered defense responses were shown among a wide variety of tomato genotypes (Bhattarai et al. 2016) and among Arabidopsis accessions (Vetter et al. 2016). These data strongly suggest different distribution and perception specificities among recognition receptors for different bacterial elicitors, including bacterial flagellin epitopes, in plants of the same or various families. Further studies, using 186 Arabidopsis, accessions by Vetter et al. (2016) demonstrated that there is no correlation in plant responses to flagellin Flg22 and EF-Tu elf18, suggesting the detection system of two canonical PAMPs have distinctly evolved. This notion could

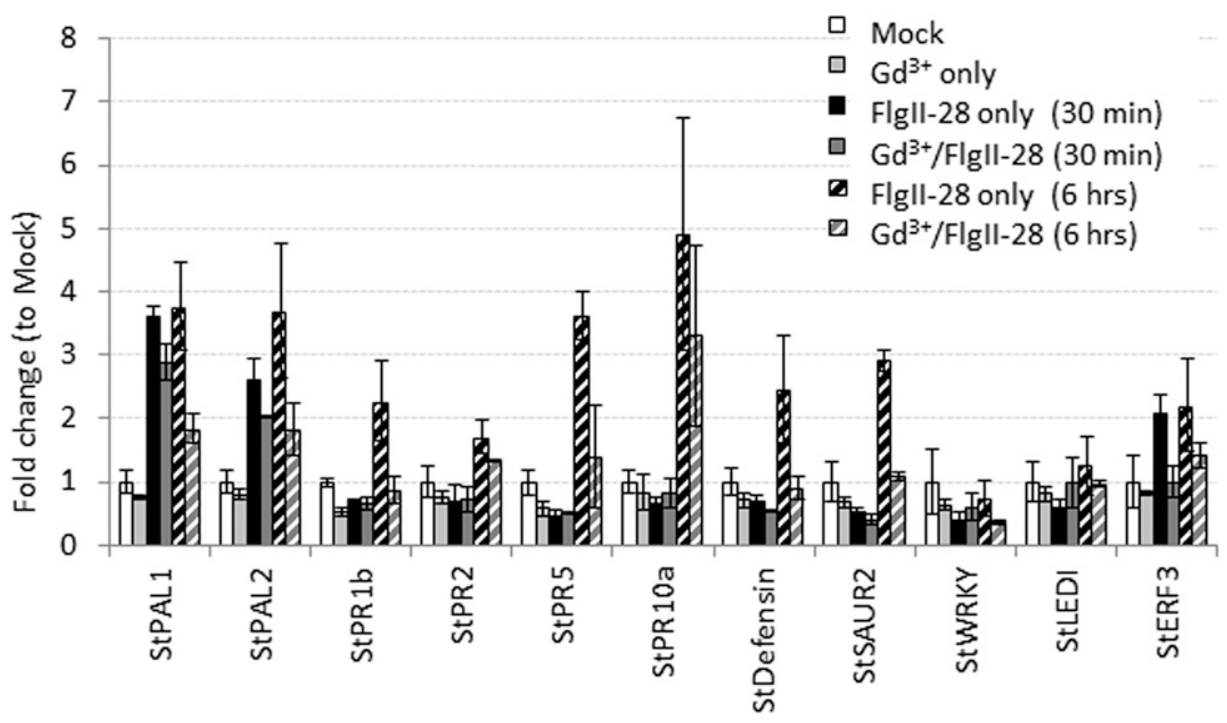

Fig. 4. FlgII-28 induced defense-related gene expression depends on $\mathrm{Ca}^{2+}$ signaling. Leaf discs from a 4-week-old potato clone (cv. Désirée) were pretreated with water (mock) or $1 \mathrm{mM} \mathrm{GdCl} 3$ for $30 \mathrm{~min}$ and were then incubated with water (mock) or $1 \mu \mathrm{M} \mathrm{FlgII}-28$ for $30 \mathrm{~min}$ and $6 \mathrm{~h}$. The expression levels of potato defense-related genes were monitored by quantitative reverse transcription-PCR. Means \pm standard error, $n=3$.
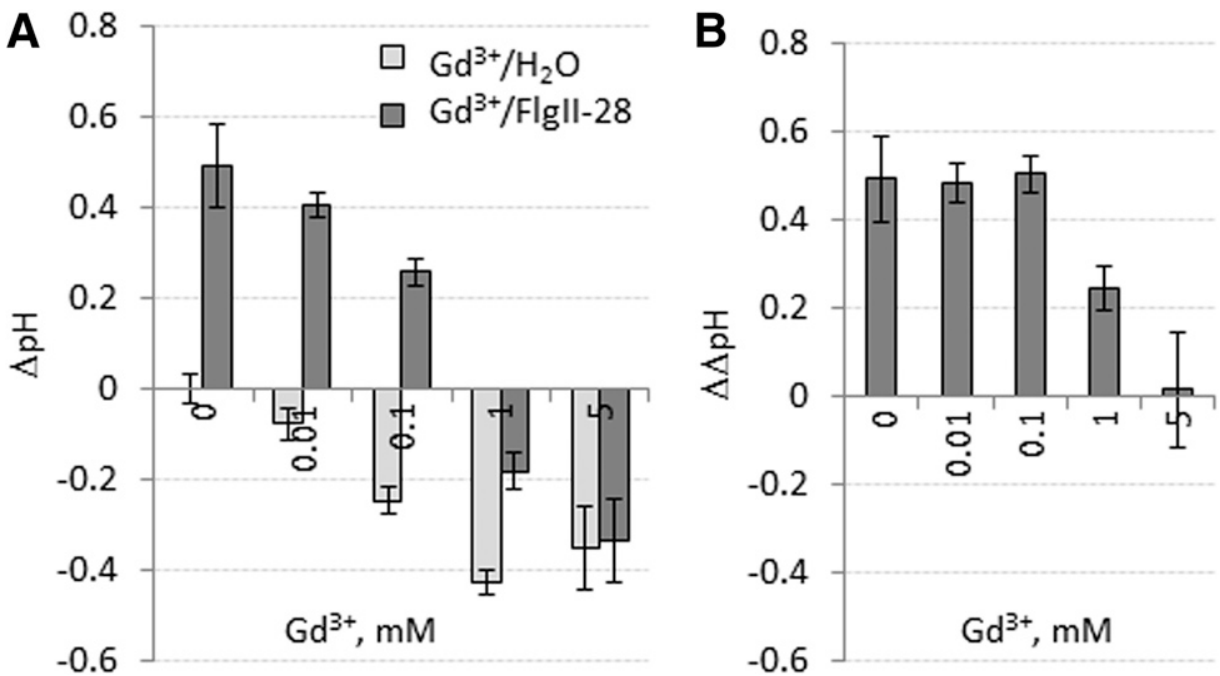

Fig. 5. FlgII-28-triggered extracellular alkalinization in potato suspension cells depends on calcium signaling. $\mathrm{GdCl}_{3}$ was applied at the final concentration of $0.01,0.1,1$, and $5 \mathrm{mM}$ for $30 \mathrm{~min}$ prior to FlgII-28 treatment at final concentration $1 \mu \mathrm{M}$. Extracellular $\mathrm{pH}$ data were measured after $20 \mathrm{~min}$. Changes in the extracellular $\mathrm{pH}(\Delta \mathrm{pH})$ were calculated by subtracting $\mathrm{pH}$ of a mock control (without $\mathrm{GdCl}_{3}$ and FlgII-28) from the data obtained. A, Dose-dependent effect of $\mathrm{Gd}^{3+}$ on $\Delta \mathrm{pH}$ in the medium was shown with or without FlgII- 28 treatment. B, Results of the subtracted data $\left(\Delta \Delta \mathrm{pH}=\Delta \mathrm{pH}_{\mathrm{Gd} 3+/ \mathrm{FlgII}-28}-\Delta \mathrm{pH} \mathrm{Gd}_{3}+/ \mathrm{H} 2 \mathrm{O}\right)$. Mean \pm standard error, $n=4$. Note that there were no $\mathrm{pH}$ changes when $\mathrm{GdCl}_{3}$ was added to cell-free medium. 
also apply to the observed differential plant responses to Flg22 and FlgII-28.

\section{MATERIALS AND METHODS}

\section{Elicitors.}

Potato systemin (StSystemin-I, AVHSTPPSKRDPPKMQTD), Flg22 (QRLSTGSRINSAKDDAAGLQIA), and FlgII-28-T1 (ESTNILQRMRELAVQSRNDSNSATDREA) were custom synthesized at $>95 \%$ purity by EZBiolab (Carmel, IN, U.S.A.). Chitin hexamer (chitohexaose) was obtained from Elicityl OligoTech (Crolles, France).

\section{Plant materials.}

Potato cvs. Désirée, Russet Burbank, Shepody, Mesa Russet, Kamiyaimo, Hokkai-Kogane, Eniwa, and Early Gem were obtained from the National Institute of Agrobiological Sciences Genebank, the United States Potato Genebank, or commercial potato producers. Potato clones were maintained in plant tissue culture jars (square vessel, $72 \times 72 \times 100 \mathrm{~mm}$ ) with $40 \mathrm{ml}$ of MS solid medium ( $\mathrm{pH}$ 5.8) containing $4.43 \mathrm{~g}$ of Murashige \& Skoog basal salts per liter (Caisson Labs, Logan, UT, U.S.A.), $30 \mathrm{~g}$ of sucrose per liter, and $8 \mathrm{~g}$ of Daishin agar per liter (Research Products International, Mount Prospect, IL, U.S.A.). The growth medium for the plants after transformation was supplemented with $100 \mathrm{mg}$ of timentin per liter (Caisson Labs, Logan, UT, U.S.A.), for inhibition of Agrobacterium tumefaciens in Agrobacterium-mediated genetic transformation (Cheng et al. 1998), and $100 \mathrm{mg}$ of kanamycin per liter (GoldBio, St. Louis), for selection of transformed tissues. Arabidopsis thaliana (Col-0) plants were maintained on MS solid medium. All plants were grown under 16-h light and 8-h dark conditions (Conviron, Winnipeg, Canada) at $22^{\circ} \mathrm{C}$.

\section{Potato transformation.}

The constructs pBINU-YA(K), in which the YFP-aequorin fusion is driven by ubiquitin promoters (Mehlmer et al. 2012), were obtained from the Arabidopsis Biological Resource Center (Columbus, OH, U.S.A.). First, the vector was transferred into A. tumefaciens (strain GV3101) using the freeze-thaw method (Höfgen and Willmitzer 1988). The A. tumefaciens transformant was cultured overnight at $28^{\circ} \mathrm{C}$ and $250 \mathrm{rpm}$ in YEB medium
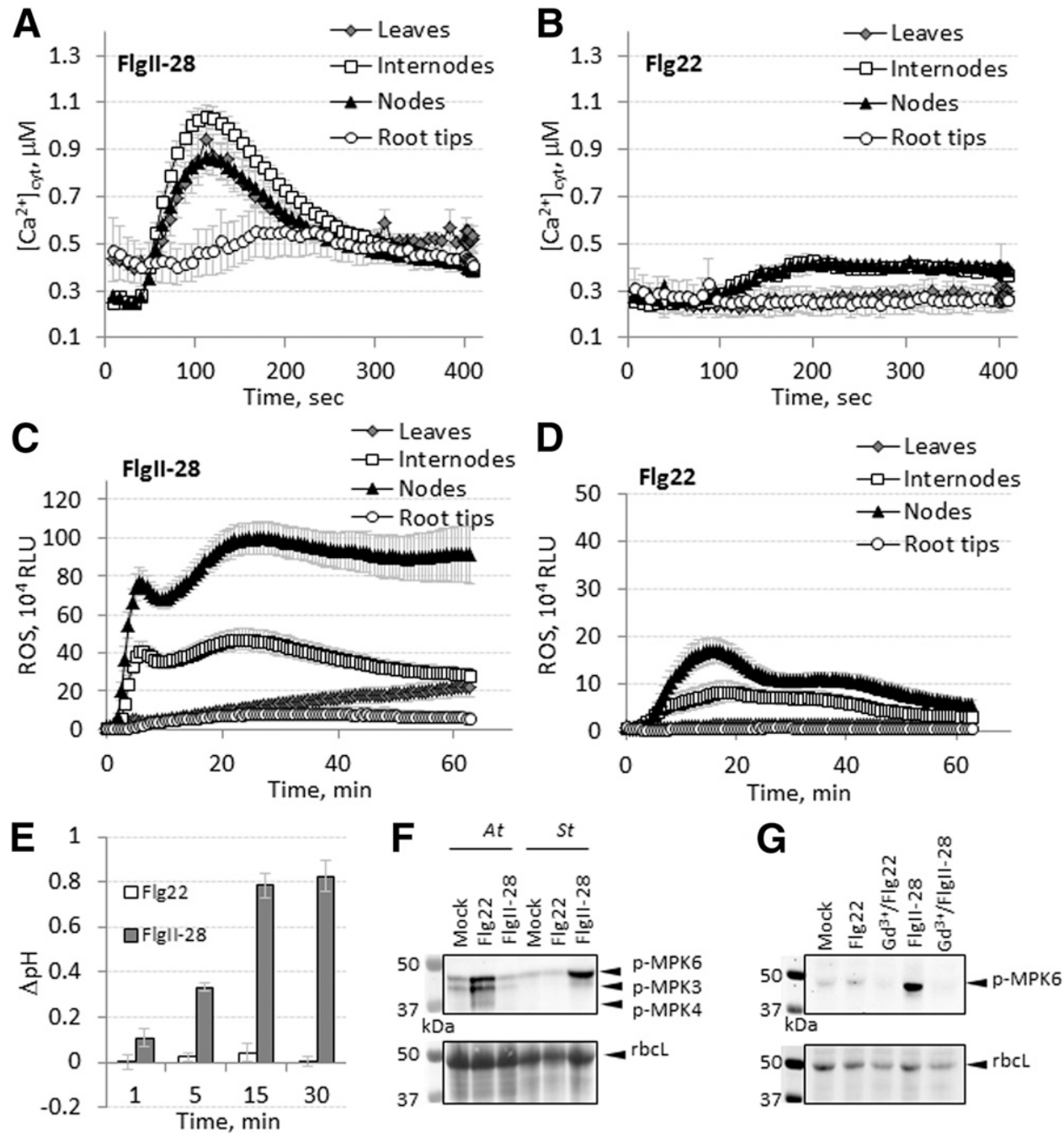

Fig. 6. FlgII-28 triggers significantly greater defense responses than Flg22 in potato. $\mathbf{A},\left[\mathrm{Ca}^{2+}\right]_{\text {cyt }}$ responses in different plant organs of aequorin-expressing transgenic potato cv. Désirée (clone 3-65) upon addition of FlgII-28 or B, Flg22, at a concentration $1 \mu \mathrm{M}$. C, Reactive oxygen species production in response to addition of FlgII-28 or D, Flg22 at a concentration of $1 \mu \mathrm{M}$ in different plant organs of potato (cv. Désirée). E, Extracellular alkalinization in potato suspension cells (cv. Russet Burbank) upon the addition of Flg22 or FlgII-28 at a concentration of $1 \mu \mathrm{M}$. F and G, Mitogen-activated protein (MAP) kinase phosphorylation in response to bacterial elicitors. A Western blot assay was performed with the p44/42 antibody. Membranes were stained with Ponceau reagent to visualize sample loading. Arrowheads indicate the bands corresponding to the phosphorylated kinases. F, Comparative effect of Flg22 and FlgII- 28 at a concentration of $1 \mu \mathrm{M}$ on MAP kinase phosphorylation in potato leaves (cv. Désirée) and Arabidopsis seedlings (ecotype Col-0). G, FlgII-28-triggered MAP kinase phosphorylation depends on $\mathrm{Ca}^{2+}$ influx. Potato leaves were preincubated with $10 \mathrm{mM} \mathrm{GdCl}_{3}$ for 30 min prior to treatment with Flg22 and FlgII-28. 
supplemented with rifampicin and gentamicin at $50 \mathrm{mg} / \mathrm{liter}$ each (Goldbio). The stable transgenic line of the potato cultivar Désirée was generated from internodal stem pieces as described by (Dinh et al. 2014).

\section{Microscopic imaging.}

Transgenic plants were imaged under a SteREO Discovery V8 stereomicroscope (Carl Zeiss Microscopy, LLC, Thornwood, NY, U.S.A.), using a GFP cube bandpass (BP) filter (BP 470/40 excitation; BP 520/30 emission). Images were obtained using a Zeiss Axiocam 105 color camera and analyzed using ZEN 2.3 lite microscope software.

\section{Immunoblots.}

To detect the YFP protein, total proteins were extracted from the whole plants of selected transgenic clones using protein extraction buffer (50 mM Tris- $\mathrm{HCl}$ [pH 7.5], $100 \mathrm{mM} \mathrm{NaCl}, 0.2 \%$ [wt/vol] Tween-20, 10\% [wt/vol] glycerol, and Halt Protease \& Phosphatase Inhibitor cocktail [ThermoScientific, Waltham, MA, U.S.A.]). Proteins were separated by sodium dodecyl sulfatepolyacrylamide gel electrophoresis (SDS-PAGE) with a $12 \%$ (wt/vol) acrylamide concentration and were then electroblotted onto a polyvinylidene diflouride (PVDF) membrane (BioRad, Hercules, CA, U.S.A.). The blot was blocked with 5\% (wt/vol) dry nonfat milk in Tris-buffered saline (TBS)-Tween $(0.1 \%$ $\mathrm{wt} / \mathrm{vol}$ ) buffer at $4^{\circ} \mathrm{C}$ overnight. YFP expression was detected using a monoclonal mouse horseradish peroxidase (HRP)conjugated anti-GFP antibody (Boustany et al. 2004) (Santa Cruz Biotechnology, Dallas TX, U.S.A.). The PVDF membranes were visualized using Pierce ECL Western blotting substrate (Thermo Scientific) with a ChemiDoc Touch imaging system (BioRad) and Image Lab 5.2.1 software. Ponceau-stained membranes were used as loading controls.

For detection of MAP kinase phosphorylation, 1-week-old whole Arabidopsis seedlings or leaf discs from 4-week-old potato cv. Désirée were incubated in sterile deionized water at room temperature overnight to reduce stress caused by transfer (for Arabidopsis) or excision (for potato). The water was discarded and the plant tissue was gently dried with Kimwipes and was treated with water (mock) or Flg22/FlgII-28. For the experiments with the $\mathrm{Ca}^{2+}$ channel blocker, the plant tissues were pretreated with $\mathrm{GdCl}_{3}$ for $30 \mathrm{~min}$ prior to the addition of the elicitor. Then, the plant tissue was frozen in liquid nitrogen and was powdered with ceramic beads for $30 \mathrm{~s}$ using a MiniBeadbeater (Biospec Products, Bartlesville, OK, U.S.A.). Total proteins were extracted directly in $2 \times$ Laemmli sample buffer with heating at $65^{\circ} \mathrm{C}$ for $7 \mathrm{~min}$. Proteins were separated by SDS-PAGE with a $10 \%$ (wt/vol) acrylamide concentration and were electroblotted onto a PVDF membrane. After blocking with $5 \%(\mathrm{wt} / \mathrm{vol})$ bovine serum albumin (Sigma, St. Louis) in TBS-Tween $(0.1 \% \mathrm{wt} / \mathrm{vol})$ buffer for $3 \mathrm{~h}$ at room temperature, phosphorylation of MAP kinases was detected by an antiphospho-p44/42 MAPK (Erk1/2) (Thr202/Tyr204) rabbit monoclonal antibody (Cell Signaling Technology, Danvers, MA, U.S.A.) and an HRP-conjugated goat antirabbit IgGsecondary antibody (Abcam, Cambridge). The PVDF membranes were visualized as described above.

\section{Aequorin luminescence-based $\left[\mathrm{Ca}^{2+}\right]_{\text {cyt }}$ measurement.}

Coelenterazine, the light-emitting aequorin substrate, was obtained from Prolume Ltd. Aequorin light emission was measured using an EnSpire multimode plate reader (Perkin Elmer, Norwalk, CT, U.S.A.). The assay was performed as described in a previous publication (Tanaka et al. 2013). Briefly, the top three leaves, nodes, and internodes from the potato clones were dissected with a $5-\mathrm{mm}$ diameter cork borer, and $10 \mathrm{~mm}$ from the root tips was cut out by a scalpel. The tissue samples were transferred to individual wells of a white 96-well plate filled with $200 \mu \mathrm{l}$ of sterile deionized water. Then, the plate was covered with the lid and was incubated overnight at $22^{\circ} \mathrm{C}$ under $16-\mathrm{h}$ light and 8 -h dark conditions. The next morning, the water was carefully removed using a multichannel pipette, $50 \mu \mathrm{l}$ of freshly prepared reconstitution buffer $(2 \mathrm{mM}$

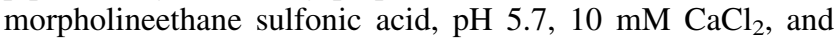
$10 \mu \mathrm{M}$ coelenterazine) was added to each well, and the plate was further incubated in the dark for $6 \mathrm{~h}$. Elicitors were added by an automatic $10-\mu l$ dispensing system. For the experiments with the $\mathrm{Ca}^{2+}$ channel blocker, the plant tissues were pretreated with $\mathrm{GdCl}_{3}$ for $30 \mathrm{~min}$ prior to the addition of elicitor. The time-dependent increase in chemiluminescence was measured by following the discharging procedure with $2 \mathrm{M} \mathrm{CaCl}_{2}$ in $20 \%$ ( $\mathrm{vol} / \mathrm{vol})$ ethanol. The data were obtained as photons per second and were further converted into $\mathrm{Ca}^{2+}$ concentration $\left[\mathrm{Ca}^{2+}\right]$ using the following equation:

$$
\begin{aligned}
{\left[\mathrm{Ca}^{2+}\right](\mathrm{nM})=\{} & {\left[\mathrm{X}^{1 / 3}+\left(\mathrm{X}^{1 / 3} \times 55\right)-1\right] / } \\
& \left.\left(1-\mathrm{X}^{1 / 3}\right)\right\} / 0.02
\end{aligned}
$$

where $X$ is the amount of light per second divided by the total light emitted after that timepoint until all the aequorin was discharged, i.e., $X=L / L_{\max }$ (Tanaka et al. 2013). The $\mathrm{Ca}^{2+}$ response of transgenic plants was compared with that of the corresponding transgenic line without stimulant treatment (mock).

\section{Luminol chemiluminescence-based ROS measurement.}

The 5-mm diameter leaf discs, 5-mm long nodes and internodes, and 10-mm long root tips were transferred to the individual wells of a white 96-well plate and were incubated overnight at $22^{\circ} \mathrm{C}$ under 16 -h light and 8-h dark conditions. Then, the plates were transferred to the dark, water was carefully removed, using a multichannel pipette, and was substituted with $50 \mu \mathrm{l}$ of the oxidative burst assay solution containing $20 \mathrm{mg}$ of HRP per liter (essentially salt free; Sigma) and $2 \mathrm{mM}$ luminol derivative (L-012; Wako, Richmond, VA, U.S.A.). For the experiments with $\mathrm{Ca}^{2+}$ channel blocker, the plant tissues were pretreated with $\mathrm{GdCl}_{3}$ for $30 \mathrm{~min}$. Then, the chemical was carefully removed using a multichannel pipette, and the oxidative burst solution was applied. The plate was kept in the dark for at least $10 \mathrm{~min}$; bacterial elicitors (Flg22 and FlgII-28) were added at a final concentration of $1 \mu \mathrm{M}$, and the time-dependent increase in chemiluminescence was monitored using a GloMax Navigator luminometer (Promega, Madison, WI, U.S.A.)

\section{Extracellular alkalinization measurement.}

The alkalinization assay was performed as described previously (Moroz et al. 2017a and b). Potato suspension cells derived from potato tubers (cv. Russet Burbank) were used in this study. For the experiment using $\mathrm{Ca}^{2+}$ channel blocker, potato suspension cells were precultured in phosphate-minusMS medium for three days followed by preincubation with $\mathrm{GdCl}_{3}$ for $30 \mathrm{~min}$ prior to FlgII-28 treatment.

\section{RNA isolation and qRT-PCR.}

Ten leaf discs for each sample were transferred to 500- $\mu$ l of sterile deionized water and were incubated overnight at $22^{\circ} \mathrm{C}$ under 16-h light and 8-h dark conditions. Then, the solution was substituted with $500 \mu \mathrm{l}$ of $1 \mu \mathrm{M}$ FlgII-28, and the samples were further incubated for $30 \mathrm{~min}$. For the experiments with $\mathrm{Ca}^{2+}$ channel blocker, the plant tissues were pretreated with $\mathrm{GdCl}_{3}$ for $30 \mathrm{~min}$ prior to the addition of elicitor. Treated leaf discs were gently dried using Kimwipes, were frozen in liquid 
nitrogen, and were then crushed with ceramic beads for $30 \mathrm{~s}$, using Mini-Beadbeater (Biospec). Total RNA isolation, cDNA synthesis, and qRT-PCR analysis were performed as previously described (Moroz et al. 2017b). Sequence information for the forward and reverse primers for the reference genes $(E F l \alpha$ and $U b q)$ and the potato defense-related genes tested in this study are listed in Supplementary Table S1.

\section{ACKNOWLEDGMENTS}

We are grateful to D. Tripathi and K. Fritch at Washington State University for technical support for potato transformation setup and potato tissue culture propagation. Special thanks to A. Smertenko and J. Jewell at Washington State University for critical comments on the manuscript.

\section{LITERATURE CITED}

Albert, M., Jehle, A. K., Lipschis, M., Mueller, K., Zeng, Y., and Felix, G. 2010. Regulation of cell behaviour by plant receptor kinases: Pattern recognition receptors as prototypical models. Eur. J. Cell Biol. 89:200-207.

Bartels, S., Lori, M., Mbengue, M., van Verk, M., Klauser, D., Hander, T., Böni, R., Robatzek, S., and Boller, T. 2013. The family of Peps and their precursors in Arabidopsis: Differential expression and localization but similar induction of pattern-triggered immune responses. J. Exp. Bot. 64:5309-5321.

Beck, M., Wyrsch, I., Strutt, J., Wimalasekera, R., Webb, A., Boller, T., and Robatzek, S. 2014. Expression patterns of flagellin sensing 2 map to bacterial entry sites in plant shoots and roots. J. Exp. Bot. 65:6487-6498.

Bhattarai, K., Louws, F. J., Williamson, J. D. and Panthee, D. R. 2016. Differential response of tomato genotypes to Xanthomonas-specific pathogen-associated molecular patterns and correlation with bacterial spot (Xanthomonas perforans) resistance. Hortic. Res. 3:16035.

Boustany, N. N., Tsai, Y. C., Pfister, B., Joiner, W. M., Oyler, G. A., and Thakor, N. V. 2004. BCL-xL-dependent light scattering by apoptotic cells. Biophys. J. 87:4163-4171.

Cai, R., Lewis, J., Yan, S., Liu, H., Clarke, C. R., Campanile, F., Almeida, N. F., Studholme, D. J., Lindeberg, M., Schneider, D., Zaccardelli, M., Setubal, J. C., Morales-Lizcano, N. P., Bernal, A., Coaker, G., Baker, C., Bender, C. L., Leman, S., and Vinatzer, B. A. 2011. The plant pathogen Pseudomonas syringae pv. tomato is genetically monomorphic and under strong selection to evade tomato immunity. PLoS Pathog. 7:e1002130.

Cheng, Z.-M., Schnurr, J. A., and Kapaun, J. A. 1998. Timentin as an alternative antibiotic for suppression of Agrobacterium tumefaciens in genetic transformation. Plant Cell Rep. 17:646-649.

Clarke, C. R., Chinchilla, D., Hind, S. R., Taguchi, F., Miki, R., Ichinose, Y., Martin, G. B., Leman, S., Felix, G., and Vinatzer, B. A. 2013. Allelic variation in two distinct Pseudomonas syringae flagellin epitopes modulates the strength of plant immune responses but not bacterial motility. New Phytol. 200:847-860.

De Vriese, K., Costa, A., Beeckman, T., and Vanneste, S. 2018. Pharmacological strategies for manipulating plant $\mathrm{Ca}^{2+}$ signalling. Int. J. Mol. Sci. 19:1506.

Dinh, P. T., Brown, C. R., and Elling, A. A. 2014. RNA interference of effector gene Mc16D10L confers resistance against Meloidogyne chitwoodi in Arabidopsis and potato. Phytopathology 104:1098-1106.

Felix, G., Duran, J. D., Volko, S., and Boller, T. 1999. Plants have a sensitive perception system for the most conserved domain of bacterial flagellin. Plant J. 18:265-276.

Fliegmann, J., and Felix, G. 2016. Immunity: Flagellin seen from all sides. Nat. Plants 2:16136.

Hao, G., Pitino, M., Ding, F., Lin, H., Stover, E., and Duan, Y. 2014. Induction of innate immune responses by flagellin from the intracellular bacterium, 'Candidatus Liberibacter solanacearum'. BMC Plant Biol. 14:211.

Hind, S. R., Strickler, S. R., Boyle, P. C., Dunham, D. M., Bao, Z., O’Doherty, I. M., Baccile, J. A., Hoki, J. S., Viox, E. G., Clarke, C. R., Vinatzer, B. A., Schroeder, F. C., and Martin, G. B. 2016. Tomato receptor FLAGELLIN-SENSING 3 binds flgII-28 and activates the plant immune system. Nat. Plants 2:16128.

Höfgen, R., and Willmitzer, L. 1988. Storage of competent cells for Agrobacterium transformation. Nucleic Acids Res. 16:9877.

Jacobs, J. M., Babujee, L., Meng, F., Milling, A., and Allen, C. 2012. The in planta transcriptome of Ralstonia solanacearum: Conserved physiological and virulence strategies during bacterial wilt of tomato. MBio 3 . e00114-e12.

Jelenska, J., Davern, S. M., Standaert, R. F., Mirzadeh, S., and Greenberg, J. T. 2017. Flagellin peptide flg22 gains access to long-distance trafficking in Arabidopsis via its receptor, FLS2. J. Exp. Bot. 68:1769-1783.
Jones, J. D., and Dangl, J. L. 2006. The plant immune system. Nature 444: 323-329.

Kadota, Y., Sklenar, J., Derbyshire, P., Stransfeld, L., Asai, S., Ntoukakis, V., Jones, J. D., Shirasu, K., Menke, F., Jones, A., and Zipfel, C. 2014. Direct regulation of the NADPH oxidase RBOHD by the PRRassociated kinase BIK1 during plant immunity. Mol. Cell 54:43-55.

Kaplan, B., Davydov, O., Knight, H., Galon, Y., Knight, M. R., Fluhr, R., and Fromm, H. 2006. Rapid transcriptome changes induced by cytosolic $\mathrm{Ca}^{2+}$ transients reveal ABRE-related sequences as Ca2+-responsive $c$ is elements in Arabidopsis. Plant Cell 18:2733-2748.

Katicheva, L., Sukhov, V., Bushueva, Bushueva, A., and Vodeneev, V. 2015. Evaluation of the open time of calcium channels at variation potential generation in wheat leaf cells. Plant Signal. Behav. 10:e993231.

Klüsener, B., Boheim, G., Liss, H., Engelberth, J., and Weiler, E. W. 1995. Gadolinium-sensitive, voltage-dependent calcium release channels in the endoplasmic reticulum of a higher plant mechanoreceptor organ. EMBO J. 14:2708-2714

Lecourieux, D., Mazars, C., Pauly, N., Ranjeva, R., and Pugin, A. 2002. Analysis and effects of cytosolic free calcium increases in response to elicitors in Nicotiana plumbaginifolia cells. Plant Cell 14: 2627-2641.

Marcec, M. J., Gilroy, S., Poovaiah, B. W., and Tanaka, K. 2019. Mutual interplay of $\mathrm{Ca}^{2+}$ and ROS signaling in plant immune response. Plant Sci. 283:343-354.

Mehlmer, N., Parvin, N., Hurst, C. H., Knight, M. R., Teige, M., and Vothknecht, U. C. 2012. A toolset of aequorin expression vectors for in planta studies of subcellular calcium concentrations in Arabidopsis thaliana. J. Exp. Bot. 63:1751-1761

Moroz, N., Fritch, K. R., Marcec, M. J., Tripathi, D., Smertenko, A., and Tanaka, K. 2017b. Extracellular alkalinization as a defense response in potato cells. Front. Plant Sci. 8:32.

Moroz, N., Huffaker, A., and Tanaka, K. 2017a. Extracellular alkalinization assay for detection of early defense response. Curr. Protoc. Plant Biol. 2: 210-220.

Nicot, N., Hausman, J. F., Hoffmann, L., and Evers, D. 2005. Housekeeping gene selection for real-time RT-PCR normalization in potato during biotic and abiotic stress. J. Exp. Bot. 56:2907-2914.

Nürnberger, T., and Brunner, F. 2002. Innate immunity in plants and animals: Emerging parallels between the recognition of general elicitors and pathogen-associated molecular patterns. Curr. Opin. Plant Biol. 5: 318-324.

Poiatti, V. A. D., Dalmas, F. R., and Astarita, L. V. 2009. Defense mechanisms of Solanum tuberosum L. in response to attack by plantpathogenic bacteria. Biol. Res. 42:205-215.

Rosli, H. G., Zheng, Y., Pombo, M. A., Zhong, S., Bombarely, A., Fei, Z., Collmer, A., and Martin, G. B. 2013. Transcriptomics-based screen for genes induced by flagellin and repressed by pathogen effectors identifies a cell wall-associated kinase involved in plant immunity. Genome Biol 14:R139.

Ruíz-Herrera, L. F., Sánchez-Calderón, L., Herrera-Estrella, L., and LópezBucio, J. 2012. Rare earth elements lanthanum and gadolinium induce phosphate-deficiency responses in Arabidopsis thaliana seedlings. Plant Soil 353:231-247.

Schaller, A., and Oecking, C. 1999. Modulation of plasma membrane $\mathrm{H}^{+}$-ATPase activity differentially activates wound and pathogen defense responses in tomato plants. Plant Cell 11:263-272.

Tanaka, K., Choi, J., Cao, Y., and Stacey, G. 2014. Extracellular ATP acts as a damage-associated molecular pattern (DAMP) signal in plants. Front Plant Sci. 5:446.

Tanaka, K., Choi, J., and Stacey, G. 2013. Aequorin luminescence-based functional calcium assay for heterotrimeric G-proteins in Arabidopsis. Methods Mol. Biol. 1043:45-54.

Veluchamy, S., Hind, S. R., Dunham, D. M., Martin, G. B., and Panthee, D. R. 2014. Natural variation for responsiveness to flg22, flgII-28, and csp22 and Pseudomonas syringae pv. tomato in heirloom tomatoes. PLoS One 9:e106119.

Vetter, M., Karasov, T. L., and Bergelson, J. 2016. Differentiation between MAMP triggered defenses in Arabidopsis thaliana. PLoS Genet. 12 : e1006068.

Vinatzer, B. A. 2012. "Listening in" on how a bacterium takes over the plant vascular system. MBio 3:e00269-12.

Wei, Y., Caceres-Moreno, C., Jimenez-Gongora, T., Wang, K., Sang, Y., Lozano-Duran, R., and Macho, A. P. 2018. The Ralstonia solanacearum csp22 peptide, but not flagellin-derived peptides, is perceived by plants from the Solanaceae family. Plant Biotechnol. J. 16:1349-1362.

Yang, X. C., and Sachs, F. 1989. Block of stretch-activated ion channels in Xenopus oocytes by gadolinium and calcium ions. Science 243 1068-1071. 